\title{
Conservation status of Prodontria (Coleoptera: Scarabaeidae) species in New Zealand
}

\section{B. I. P. Barratt}

Published online: 23 January 2007

(C) Springer Science+Business Media B.V. 2007

\section{Erratum to: J Insect Conserv \\ DOI 10.1007/s10841-006-9015-z}

Due to an unfortunate error, an incorrect version of Fig. 1 and Table 1 has been used in the above mentioned publication. On the following pages, the correct reproductions have been published and should be treated as definitive by the reader.
The online version of the original article can be found at http:// dx.doi.org/10.1007/s10841-006-9015-z

\section{B. I. P. Barratt $(\bowtie)$}

AgResearch Invermay, Invermay Agricultural Centre, Puddle Alley, Private Bag 50034, Mosgiel, New Zealand e-mail: barbara.barratt@agresearch.co.nz

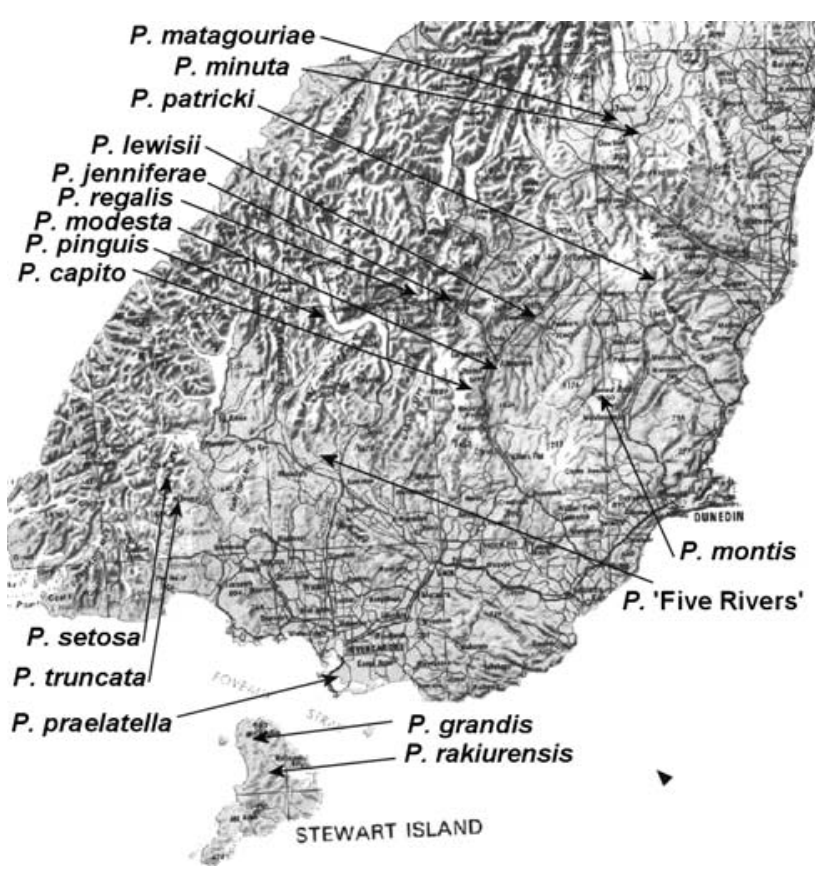

Fig. 1 Map of the southern South Island of New Zealand showing type localities for Prodontria species, excluding $P$. longitarsis (Snares Islands). Prodontria 'Five Rivers' shows the locality where this species was found 


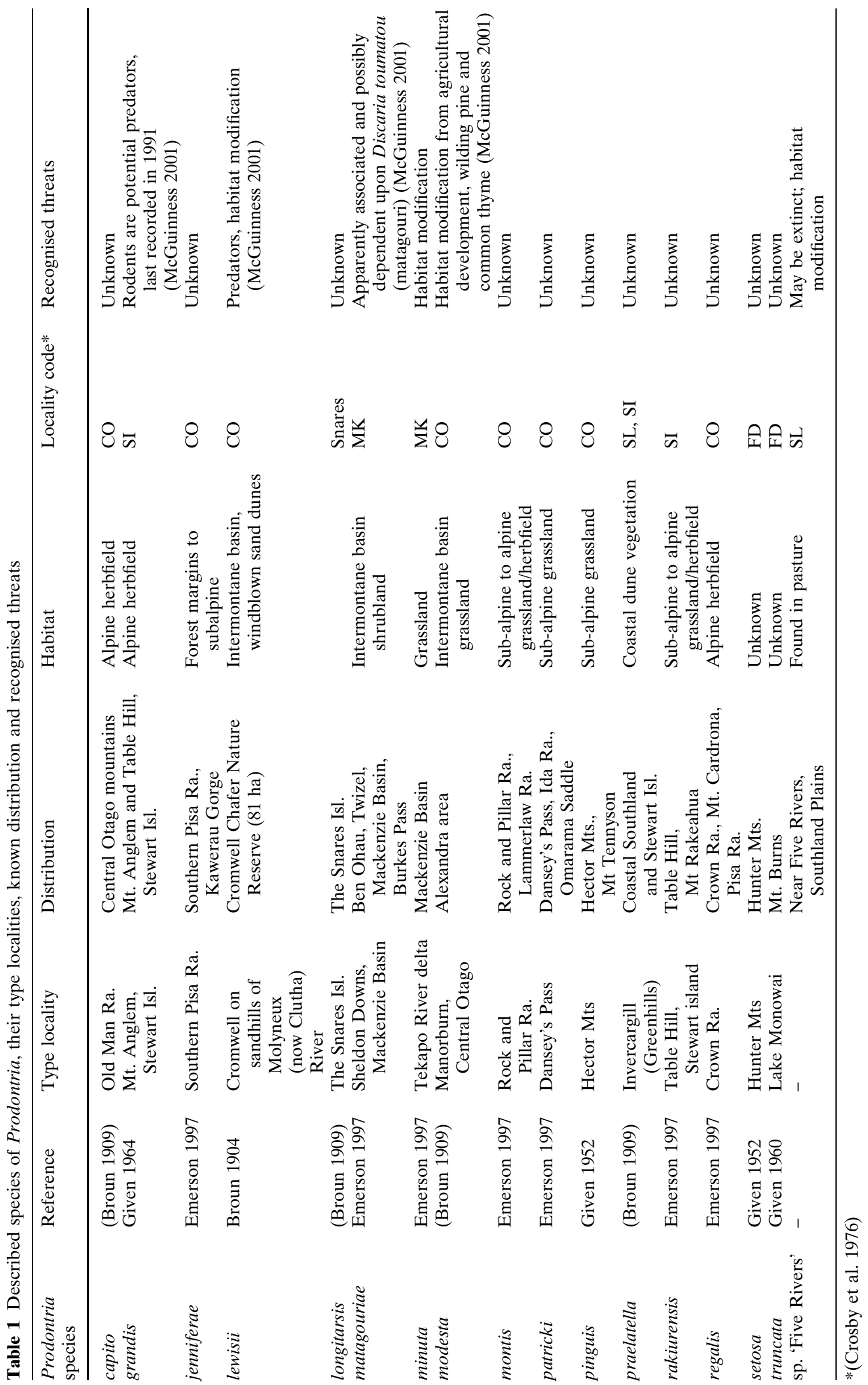

